\title{
Differential Staged Sacral Reflexes: Methodology and Normal Values from 51 Healthy Subjects and 134 Patients with Pudendal Neuralgia
}

\author{
Eric de Bisschop ${ }^{1,2}$, Rajeshree Nundlall, ${ }^{2, *}$ \\ ${ }^{1}$ Department of surgery, Casamance Clinic, 33, Boulevard des Farigoules, 13400, Aubagne, France \\ ${ }^{2}$ Angiology, private office, 55 avenue des Goums, 13400, Aubagne, France
}

\begin{abstract}
Objective: to develop a reproducible method for electrophysiological study of pudendal nerves which can explore the different risk areas: sacral spinal, infrap iriformis area and ischiorectal fossa. This method is called "differential staged sacral re flexes (DSSR)". 51 patients not suffering from pudendal neuralgia and 134 patients with pudendal neuralgia have been selected. The sacral reflexes (SR) are made at the ventral and dorsal quadrants of the anal sphincter and at the pubococcygeus muscle. Considering the values of the DSSR obtained on healthy subjects and on patients with pudendal neuralgia, maximu $\mathrm{m}$ threshold values have been established: a significant difference between ventral and dorsal quadrant of the anal sphincter: damage orientation at the level of the ischiorectal fossa; significant diffe rence between dorsal quadrant of the anal sphincter and pubococcygeus muscle: damage orientation at the level of the infrapiriformis area. SR delayed uniformly at the three afore-mentioned muscles: damage orientation at the level of the sacral spinal. The DSSR allow in a reproducible way to investigate the pudendal nerve in all areas suitable to entrap this nerve, which is impossible with the method of pudendal nerve terminal motor latency (PNTML).
\end{abstract}

Keywords Differential Staged Sacral Reflexes, Pudendal Nerve, Elevator Ani Nerve, Piriformis Area, Ischiorectal Fossa

\section{Introduction}

The conventional technique of electrophysiology of the pudendal nerve is to measure the distal motor latency (PNTML)[1] by endocavitary stimulation, rectal and / or vaginal, at the level of the ischial spine with collection at the anal sphincter

This method sins however due to the lack of reproducibility and of sensibility[2-5]: PNTML can be lengthened without corresponding to a pudendal neuropathy and being normal without eliminating it. Several factors can interfere with nervous time conductions: vascular, synaptiques distales endings, vegetative reactivities, variability of the answers in the time and according to the operator.

The sacral reflexes[6-8] studied on the ventral and dorsal quadrants of the anal sphincter and on the pubococcygeus muscle (staged sacral reflex) showed significant differences in responses to establish normal values, beyond and which according to the responses, a truncal compression (TC) or an intra-spinal conflict may be mentioned. In case of TC, these

* Corresponding author:

rajeshree@free. fr (Rajeshree Nundlall)

Published online at http://journal.sapub.org/cmd

Copyright (C) 2012 Scientific \& Academic Publishing. All Rights Reserved staged sacral reflexes can also direct the compressive site to the infrapiriformis area and/or to the ischiorectal fossa.

\section{Anatomical Recall (Fig. 1)}

The PN is a mixed nerve taking its origin at the $\mathrm{S} 2, \mathrm{~S} 3$ and S4 roots, with a possible contribution of S1[9]. Then, the $\mathrm{PN}$ cross the infrapiriformis area[10] limited from the lower edge of the piriformis muscle to the sacrospinous ligament (SSL). The PN then passes beneath the SSL. The inferior rectal nerve (IRN), the first collateral PN, born before the coming of the ischiorectal fossa (IRF), does not go under the falciform process (FP) or in the Alcock canal (AC). It will innervate the dorsal quadrant of the anal sphincter (AS). The PN truncal pathway, became perineal nerve (PEN), continues under the FP and the AC (duplication of the fascia of the Obturator internus). It will innervate the ventral quadrant of AS.

The levator ani nerve (LAN) runs up the anterior coccygeal muscle. It thus does not pass under the SSL or under the FP and thus avoids the AC. It innervates, among other things, the pubococcygeus muscle (PCM)[11].

Note that the PN has many anatomical variations:

After dissection of the body 7[7-8]: The origin of the IRN is in all cases before entering the ischiorectal fossa (IRF) with a direct path to the posterior of the anal canal, can 
passes under/throught or above the SSL. Then it runs in the lateral space of the ischiorectal fossa nerve. It never passes in the AC (duplication of the fascia of the Obturator internusl). After dissection of 37 bodies[12], it is found from a trunk under the SSL in $56.2 \%, 11 \%$ in two trunks, 2 trunks with 1 IRN perforating the SSL in $11 \%, 3$ trunks with a IRN does not pierce SSL in the $9.5 \%$ and $12.3 \%$ in three trunk.

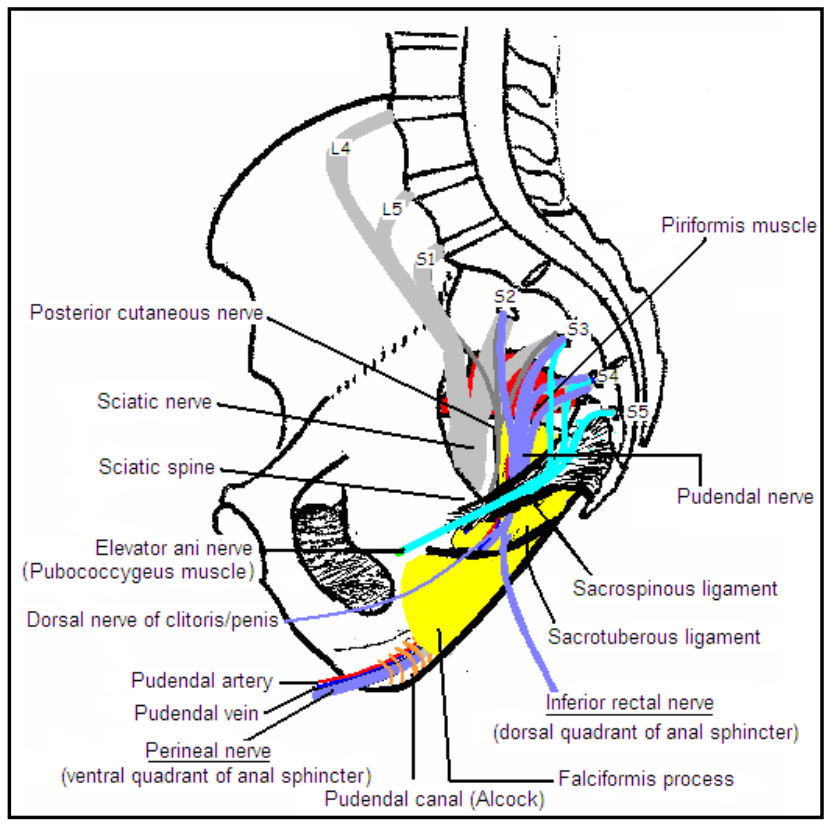

Figure 1. Nerve supply pelvic floor anat omy

\section{Sacral Reflex[13-14] (Fig. 2)}

The afferent way consists of sensory fibers of PN stimulated electrically at the dorsal nerve of the clitoris / penis.

It is essential to consider that the nerve is made up of many nerve fibers (NF). Increasing the intensity of stimu lation has the effect a gradual increase in the number of NF recruited (spatial summation). The receiver corresponds to a sensitive current-transducer number, from which the stimulation intensity (I) is converted to a number $(\mathrm{N})$ of activated NF[N $=\mathrm{f}(\mathrm{I})]$. On a normal subject, the threshold intensity is the minimum number of NF whose action potentials arriving phase have a resultant intensity sufficient to trigger the reflex.

But if on the afferent way the individual nervous conductions are desynchronized or if a denervation is important, the reflex is absent or requires a higher stimulation intensity.

In this case, D. Vodusek[15] shown we can get the reflex with 2 or many coupled stimulations. We get the same effect by recording the reflex during voluntary contraction force of the anal sphincter (personal method).

The afferent message will be articulated relating to a transfer module located at $\mathrm{S} 2-\mathrm{S} 4$ spinal cord with a systemof interneurons. This message, via the transfer module, will excite the outflow tract at the start of the ventral horn of the spinal cord (S2-S4) located in the nucleus of Onuf. All of the reflexarc takes about $35 \mathrm{~ms}(\mathrm{~N}<44 \mathrm{~ms})$.

Muscle response can be recorded at all perineal pelvic muscles.

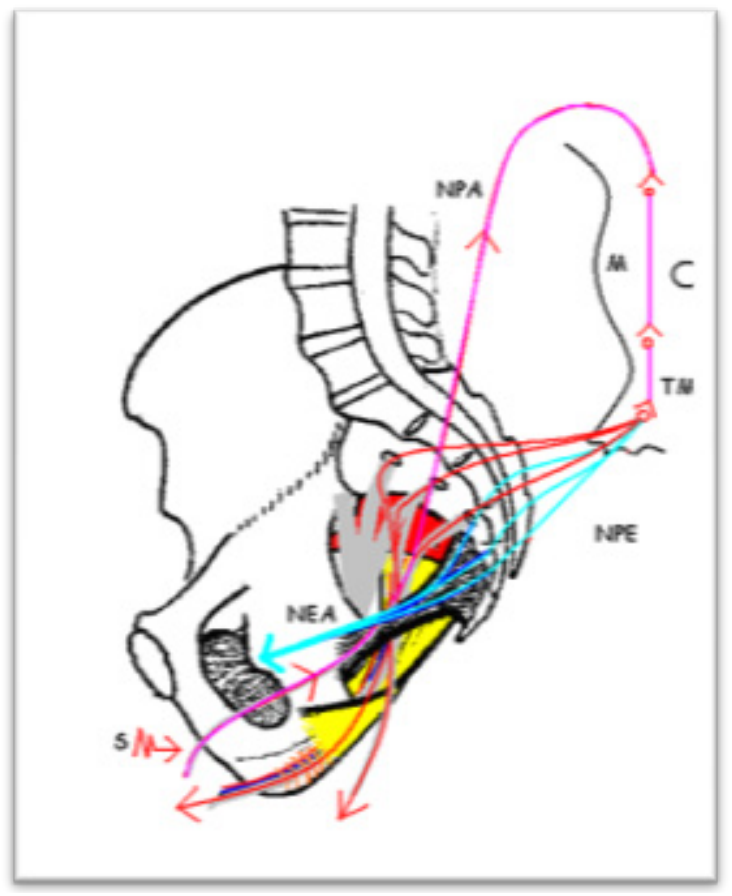

Figure 2. Sacral reflex S: Stimulation; NPA: afferent way of PN; M: medullar level S2, S3 and S4; TM:transfer module; NPE efferent way of PN; NEA: elevator ani nerve

\section{Materials}

a. For the puncture of the ventral and dorsal quadrant of the anal sphincter, is used a disposable concentric needle electrode $25 \mathrm{~mm}$ X $30 \mathrm{G}$

b. For the puncture of the pubococcygeus muscle, is used a disposable concentric needle electrode $50 \mathrm{~mm} \mathrm{X} 26 \mathrm{G}$.

c. 51 healthy subjects divided into 38 wo men and 13 men were selected. These subjects are free of pain pelvic-perineal and / or functional sign pelvic-perineal and / or pelvic viscera of ptosis. Carriers of blemishes that may be associated with neuropathy were eliminated from the study.

The 13 men were investigated for evaluation before treatment by finasteride ( 9 for alopecia and 4 for benign prostatic hyperplasia). 38 wo men were investigated for stress incontinence by cervico-urethral hypermobility (staged sacral refle xes made before the urodynamic investigations)

Patient age is between 26 and 83 years, with an average of 58 years.

d. 134 patients, included 83 women and 51 men suffering from pudendal neuralgia with a positive response to the infiltration of truncal PN.

\section{Methods}

a. Location of the pubococcygeus muscle (fig. 3) 


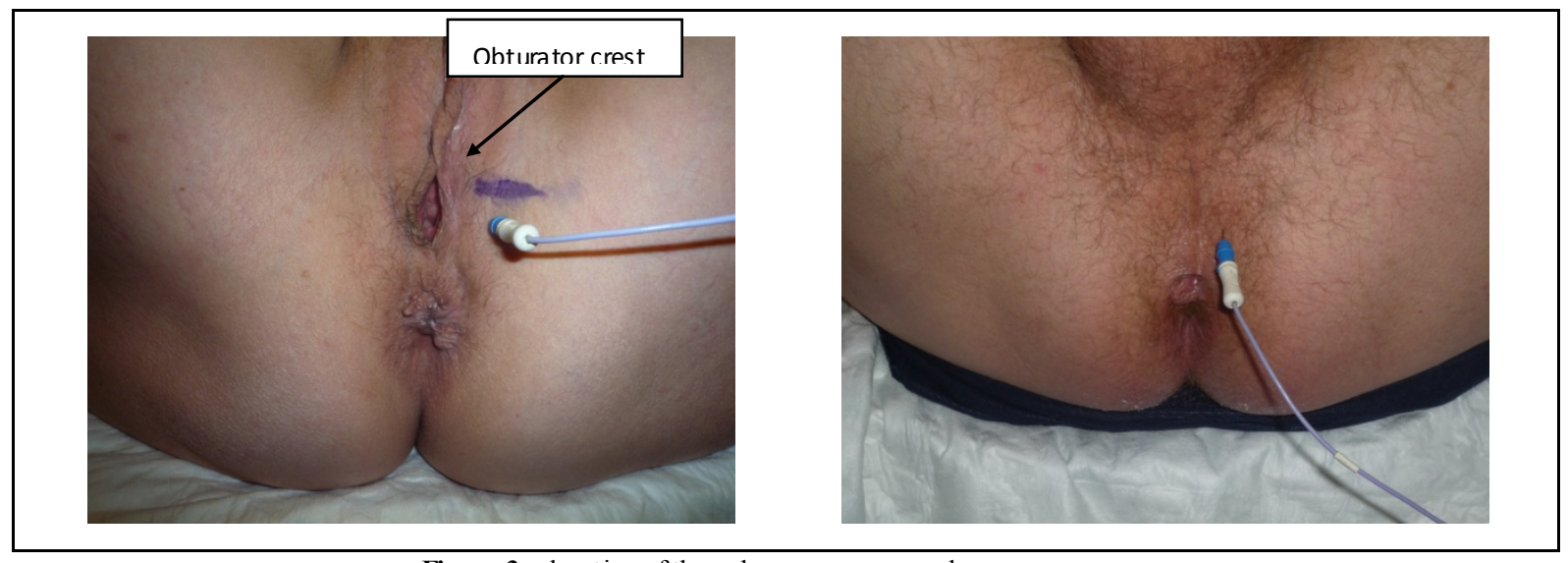

Figure 3. location of the pubococcygeus muscle

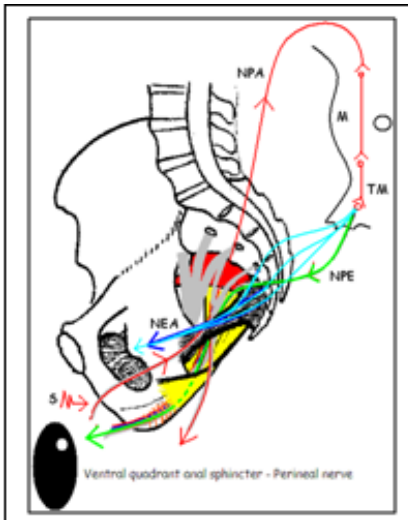

G pudendal - perineal nerve

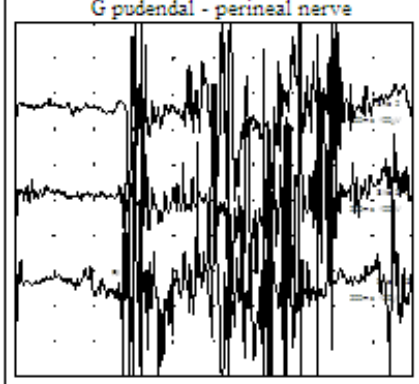

Ventral quadrant $52.2 \mathrm{~ms}$
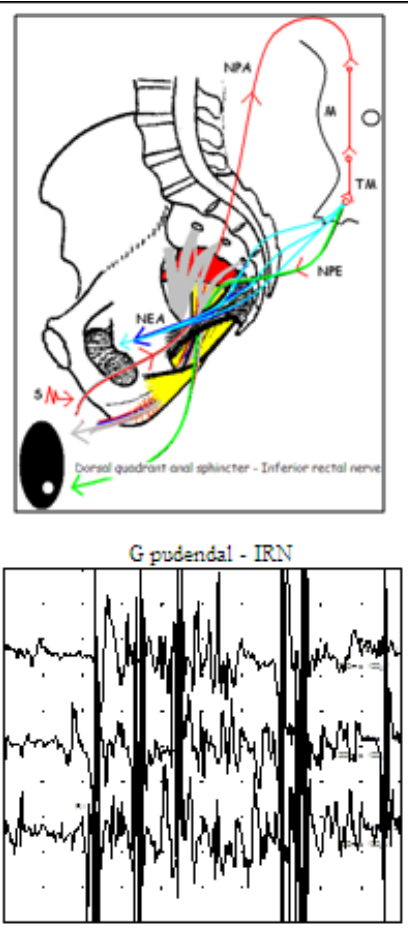

Dorsal quadrant $40 \mathrm{~ms}$
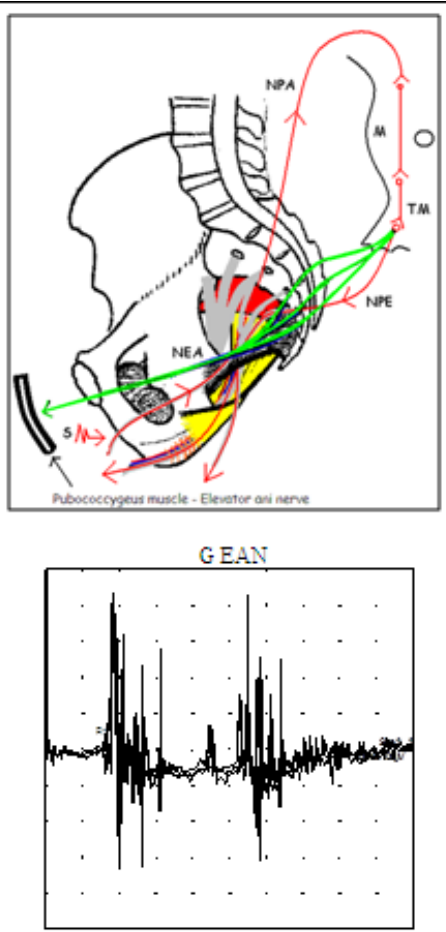

Pubococygevs muscle $34.1 \mathrm{~ms}$

Figure 4. Schematic representation of DSSR with-drawn type of example: damage orientation at the level at the entire route IPA/IRF $S M:$ Dorsal nerve of clitoris/penis st imulations

For the puncture of the pubococcygeus muscle, we use a disposable concentric needle electrode $50 \mathrm{~mm} \mathrm{X} 26 \mathrm{G}$. Women and men, the needle is introduce at 4 to $5 \mathrm{~cm}$.

* Women: Puncture just below the obturator crest, lateral to the lower part of the labia majora. Inclination of the needle at $15-20^{\circ}$ upwards

* Men: punture $1 \mathrm{~cm}$ lateral to the raphe of perineum. Inclination of the needle at $15-20^{\circ}$ upwards

b. Staged sacral reflexes (fig. 4)

Based on the general principle of the sacral reflex, the staged sacral reflexes use the collateral dichotomy of PN and the innervation of the EAN. The EAN does not pass through areas likely to compress the $\mathrm{PN}$, serves as a reference minimum conduction delay. The perineal nerve, passing through all the areas likely to compress the PN, serves as a reference maximum conduction delay.
By comparing the sacral reflex obtained on the ventral quadrant of the anal sphincter (perineal nerve), and those obtained in the dorsal quadrant of the anal sphincter (IRN), never passing through the IRF, we study nerve conduction in the IRF and the same in the Alcock canal

By comparing the sacral reflex obtained on the dorsal quadrant of the anal sphincter (IRN), and those obtained in the pubococcygeus muscle (EAN), we study nerve conduction in the infrap iriformis area.

Reporting results in anatomical diagram:

-Ventral quadrant (Q1) of the anal sphincter (perineal nerve): in forms on the overall conduction of PN: the neural pathway will go through all the areas likely to conflict with the PN: spinal sacral roots, IPA, IRF and AC

-Dorsal quadrant of the anal sphincter (IRN) from the ventral quadrant of the anal sphincter: this path does not pass 
through the IRF, the falciformis process and AC. It therefore informs the distal nerve conduction PN (IRF and AC). Subtracting the value of SR obtained at the ventral quadrant to that obtained at the dorsal quadrant. If the NRI forward pass of SSL (anatomical variation), the difference of the values obtained information on all of the truncal motor conduction PN (IPA, IRF and AC).

-Pubococcygeus muscle (Q3) (PCM) from the dorsal quadrant: information on nerve conduction of the $\mathrm{PN}$ at the IPA. Subtracting the value of SR obtained at the dorsal quadrant to that obtained at the pubococcygeus muscle. If the IRN forward pass of SSL, the value obtained will be similar (not significant) than that obtained on the dorsal quadrant.

\section{Results}

By studying the values obtained on the sacral reflexes on pelvic floor muscles with the study explored the differences recorded between each of these muscles in all healthy subjects and patients with pudendal neuralgia (Table 1), detailing the women (Table 2 ) and men (Table 3), we defined the minimum and maximum nervous time conduction between the quadrant ventral Q1 and dorsal quadrant Q2 and between Q2 and pubococcygeus muscle Q3 of 51 healthy subjects (table 4) and the 134 patients with pudendal neuralgia (table 5)

Table 1. Sacral reflexes values obtained on the perineal muscles explored on the healthy subjects and on the patients with pudendal neuralgia

\begin{tabular}{|c|c|c|c|c|c|c|}
\hline \multicolumn{7}{|c|}{51 healthy subjects (S) } \\
\hline & Q1 S & Q1 NP & Q2 S & Q2 NP & Q3 S & Q3 NP \\
\hline Max (ms) & 43,6 & 55,6 & 42,6 & 55,6 & 41,8 & 42,2 \\
\hline Min (ms) & 32,6 & 42,6 & 30,2 & 32,6 & 29,4 & 28,8 \\
\hline Moy (ms) & 38,3 & 50,2 & 36,9 & 40,4 & 36,1 & 35,6 \\
\hline
\end{tabular}

Table 2. Sacral reflexes values obtained on the perineal muscles explored on the healthy women and on the women with pudendal neuralgia

\begin{tabular}{|c|c|c|c|c|c|c|}
\hline \multicolumn{7}{|c|}{ 38 healthy women (S) } \\
\hline & Q1 S & Q1 NP & Q2 S & Q2 NP & Q3 S & Q3 NP \\
\hline Max (ms) & 43,6 & 55,6 & 42,6 & 55,6 & 41,8 & 41,8 \\
\hline Min (ms) & 32,6 & 42,8 & 30,2 & 34,8 & 29,4 & 29,4 \\
\hline Moy (ms) & 38,6 & 52,4 & 37,1 & 42,2 & 36,3 & 36,3 \\
\hline
\end{tabular}

Table 3. Sacral reflexes values obtained on the perineal muscles explored on the healthy men and on the men with pudendal neuralgia

\begin{tabular}{|c|c|c|c|c|c|c|}
\hline \multicolumn{9}{|c|}{13 healthy men (S) } \\
\hline & Q1 S & Q1 NP & Q2 S & Q2 NP & Q3 S & Q3 NP \\
\hline Max (ms) & 41,8 & 53,4 & 40 & 53,2 & 39,8 & 42,2 \\
\hline Min (ms) & 33 & 38,6 & 31,8 & 32,6 & 31 & 28,8 \\
\hline Moy (ms) & 38 & 46,8 & 36,7 & 39,8 & 35,9 & 35 \\
\hline
\end{tabular}

Table 4. Nerve conduction time between ventral quadrant Q1 and dorsal quadrant Q2 and between Q2 and pubococcygeus muscle Q3 on the 51 healthy subjects

\begin{tabular}{|c|c|c|}
\hline & $\mathrm{Q} 1-\mathrm{Q} 2$ & $\mathrm{Q} 2-\mathrm{Q} 3$ \\
\hline $\begin{array}{c}\text { Femmes temps max en ms } \\
\text { Women max time in ms }\end{array}$ & 3 & 0 \\
\hline $\begin{array}{c}\text { Femmes temps min en ms } \\
\text { Women min time in ms }\end{array}$ & 0 & 1.4 \\
\hline $\begin{array}{c}\text { Hommes temps max en ms } \\
\text { Men max time in ms }\end{array}$ & 2 & 0 \\
\hline $\begin{array}{c}\text { Hommes temps min en ms } \\
\text { Men mintime in ms }\end{array}$ & 0 & 0 \\
\hline
\end{tabular}

Table 5. Nerve conduction time between ventral quadrant Q1 and dorsal quadrant Q2 and bet ween Q2 and pubococcygeus muscle Q3 on the 134 pat ients with pudendal neuralgia

\begin{tabular}{|c|c|c|}
\hline \multicolumn{3}{|c|}{ 83 Women with pudendal neuralgia - 51 Men with pudendal neuralgia } \\
\hline & $\mathrm{Q} 1-\mathrm{Q} 2$ & $\mathrm{Q} 2-\mathrm{Q} 3$ \\
\hline Women max time in $\mathrm{ms}$ & 17,6 & 10,2 \\
\hline Women min time in $\mathrm{ms}$ & 3,2 & 2,4 \\
\hline Men max time in $\mathrm{ms}$ & 14,2 & 8,8 \\
\hline Men min time in $\mathrm{ms}$ & 2,2 & 1,6 \\
\hline
\end{tabular}

Table 6. Normal nerve conduction time between ventral quadrant Q1 and dorsal quadrant Q2 and bet ween Q2 and pubococcygeus muscle Q3

\begin{tabular}{|c|c|c|}
\hline & $\mathrm{Q} 1-\mathrm{Q} 2$ & $\mathrm{Q} 2-\mathrm{Q} 3$ \\
\hline Women in $\mathrm{ms}$ & $\mathrm{N} \leq 3$ & $\mathrm{~N} \leq 2.2$ \\
\hline Men in $\mathrm{ms}$ & $\mathrm{N} \leq 2$ & $\mathrm{~N} \leq 1.4$ \\
\hline
\end{tabular}


Table 7. compressive topographic orientation

\begin{tabular}{|c|c|c|}
\hline Table 7 & $\begin{array}{c}\mathrm{Q} 1-\mathrm{Q} 2 \\
q>3 \mathrm{~ms}-\hat{\delta}>2 \mathrm{~ms}\end{array}$ & 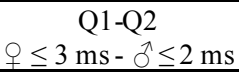 \\
\hline $\begin{array}{c}\mathrm{Q} 2-\mathrm{Q} 3 \\
q>2.2 \mathrm{~ms}-\hat{\jmath}>1.4 \mathrm{~ms}\end{array}$ & $\begin{array}{c}\mathrm{CIP}+\mathrm{FIR} \\
\mathrm{RS}<>\mathrm{N}\end{array}$ & $\begin{array}{c}\text { CIP } \\
\mathrm{RS}<\mathrm{N}\end{array}$ \\
\hline $\begin{array}{c}\text { Q2-Q3 } \\
q \leq 2.2 \mathrm{~ms}-\hat{\delta} \leq 1.4 \mathrm{~ms}\end{array}$ & $\begin{array}{c}\mathrm{CIP}+/- \text { FIR } \\
\mathrm{RS}<>\mathrm{N}\end{array}$ & $\begin{array}{c}\text { sacral spine } \\
\text { RS }>N\end{array}$ \\
\hline
\end{tabular}

We were able to define maximum normative values between these muscles (Table 6) provide guidance and topographic compressive (Table 7).

In the particular case of a conflict purely root S2, S3 or S4 kind Tarlov cyst, it will most often neurogenic signals without focal slowing of nervous conductions.

Legend:

SR $>$ N: the SR are higher than normal on all the muscles explored, with no significant difference in terms of Q1, Q2 and Q3

$\mathrm{SR}<>\mathrm{N}$ : The $\mathrm{SR}$ is higher or lower than normal but in all cases with significant differences between Q1 and Q2 and / or Q2 and Q3.

\section{Discussion}

a. Advantage of the differential staged sacral reflexes:

- Reproducible method

- Allow to explore the PN, from the sacral spine to the distal part via the sacral roots.

- Allow to act out a TC at the IPA, can not be accessed with the PNTML

- Directs the head injury (sacral spine, IPA, IRF)

- Few false positives

- No false negatives

b. Disadvantages:

Appears to have $7.8 \%$ false positives. Note that $80 \%$ of these false positives have shown clinical signs of PN contralateral side to evoke electrophysiological within 2 years that followed exploration EMG.

Study conducted on unilateral 64 pudendal neuralgia. 5 false positive contralateral side. 4 pudendal neuralg ia have their bilateralized in two years that have followed. Can thus be estimated at $1.6 \%$ real rate of false positives.

\section{Conclusions}

Compared to the motor latency of the pudendal nerve (PNTML), the differential staged sacral reflexes can, reproducibly, explore the whole pathway of the pudendal nerve and sacral spine. A PN entrapment compression located in the infrapiriformis area ( $70-80 \%$ of cases) may be evoked, which is technically impossible with the PNTML.

\section{REFERENCES}

[1] Kiff E, Swash M. Slowed conduction in the pudendal nerves in idiopathic (neugenic) faecal incontinence. $\mathrm{Br} \mathrm{J}$ Surg 1984;71:614-16

[2] Bussen D, Sailer M, Fuchs K-H, Thiede A. Reliability of Pudendal Nerve Terminal Motor Latency. Coloproctology 2003;5:261-265

[3] de bisschop E, Bautrant E. EMG: which one and why?. Considerations regarding Pudendal Nerve Terminal Motor Latencies (PNTML). 31st meeting of the International Urogynecologycal Association (IUGA 2006). September 6-9. 2006. Athens

[4] Le Tallec de Certaines H, Veillard D, Dugast J, Estèbe J-P, Kerdraon J, Toulouse $\mathrm{P}$ et al. Comparaison entre la latence distale motrice du nerf pudendal, la topographie de la douleur périnéale et le résultat d'infiltrations. Analy se pour 53 patients. Annales de réadaptation et de médecine physique 50 (2007) 65-69

[5] Altomare D, Rinaldi M, Petrolino M, Ripetti V, Masin A, Ratto $\mathrm{C}$ and Al. Reliability of electrophysiologic anal tests in predicting the outcome of Sacral nerve modulation for fecal incontinence. American Society of Colorectal Surgeons. 2004; $47: 853-857$

[6] de Bisschop E, Bautrant E. Nouveaux concepts d'explorations électrophysiologiques du nerf pudendal dans le cadre de la névralgie pudendale. Electrophysiologie de diagnostic. Electrophysiologie per-opératoire. Pelvimag 2006;55:12-4

[7] Spinosa J-P, de Bisschop E, Laurençon J, Kuhn G, Dubuisson J-B, Riedederer B-M. Les réflexes sacrés étagées dans l'étude anatomique de la névralgie pudendale: validation an atomique. Rev Med Suisse 2006;2:2416-2421

[8] Spinosa J-P, de Bisschop E, Laurençon J, Kuhn G, Riedederer B-M. Differential staged sacral reflexes allow a localization of pudendal neuralgia. Pelviperineology. 2009;28:24-8

[9] Shafik A, el-Sherif M, Youssef A, Olfat ES. Surgical anatomy of the pudendal nerve and its clinical implications. Clin Anat. $1995 ; 8(2): 110-5$

[10] Herbreteau Guillaume. Base anatomique du syndrome du piriforme - Mémoire réalisé dans le cadre du certificat d'Anatomie, d'Imagerie et de Morphogenèse - Université de Nantes - 2007-2008

[11] Bogdan A. Grigorescu, George Lazarou, Todd R. Olson, Sherry A. Downie, Kenneth Powers, Wilma Markus Greston and Magdy S. Mikhail. Innervation of the levator ani muscles: description of the nerve branches to the pubococcygeus, iliococcygeus, and puborectalis muscles. International Urogynecology Journal. 2008;19:1107-116

[12] Mahakkanukrauh P, Surin P, Vaidhayakarn P. Anatomical study of the pudendal nerve adjacent to the sacrospinous 
ligament. Clin Anat. 2005 Apr;18(3):200-5

[13] de Bisschop G, Spinosa J-P, de Bisschop E, Nundlall R. Considérations anatomophysiologiques à propos du réflexe sacré. Rev Med Suisse 2008;4:546-549
[14] Uher E-M, Swash M. Sacral reflexes Phy siology and clinical application Diseases of the Colon \& Rectum. 1998;41(9)

[15] Vodusek D.B., Janko M. Lokar J. Direct and reflex responses in perineal muscles on electrical stimulation. J. Neurol Neurosurg Psy chiatry 1983; 46:67-71 